\title{
Detecção de Cutibacterium acnes em amostras de tecidos de cirurgias limpas primárias do ombro - Parte I
}

\section{Detection of Cutibacterium acnes in Tissue Samples from Primary Clean Shoulder Surgeries - Part I}

\author{
Alberto Naoki Miyazaki1,2® Caio Santos Checchia10 João Manoel Fonseca Filho ${ }^{2}$ (1)

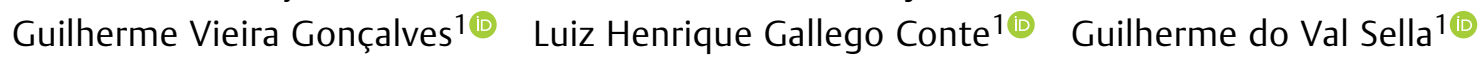 \\ ${ }^{1}$ Departamento de Ortopedia e Traumatologia, Faculdade de Ciências \\ Médicas, Santa Casa de São Paulo, São Paulo, SP, Brasil \\ Endereço para correspondência Guilherme Vieira Gonçalves, MD, \\ 2 Hospital Alemão Oswaldo Cruz em São Paulo, São Paulo, SP, Brasil \\ Santa Casa de Misericórdia de São Paulo, Departamento de Ortopedia \\ e Traumatologia “Pavilhão Fernandinho Simonsen,", Rua Dr. Cesário \\ Rev Bras Ortop 2022;57(4):606-611. \\ Mota Júnior, 112, Vila Buarque, 01220-020, São Paulo, SP, Brasil \\ (e-mail: guilherme.vg.90@gmail.com).
}

\section{Resumo \\ Palavras-chave \\ - cutibacterium acnes \\ - infecções por bactérias gram- positivas \\ - ombro}

Objetivo Identificar agentes bacterianos em amostras de cirurgias do ombro de pacientes sem histórico de infecção e de cirurgias prévias no ombro.

Métodos Amostras de tendão, bursa e osso foram coletadas no intraoperatório, armazenadas em frascos estéreis a seco e enviadas para análise de crescimento de cultura em meios para agentes aeróbios e anaeróbios no laboratório credenciado ao hospital. Foram analisados os resultados de 141 amostras de 47 ombros.

Resultados Obtivemos resultados de culturas negativas em 46 casos (97,8\%) e em 140 amostras (99,2\%). Apenas um paciente apresentou resultado positivo, com crescimento bacteriano do Staphylococcus hominis em uma das três amostras coletadas.

Conclusões Não evidenciamos taxas de crescimento bacteriano condizentes com a literatura internacional, alertando para a baixa eficácia dos métodos laboratoriais utilizados no nosso país.

Objective The present study aimed to identify bacterial agents in shoulder surgery specimens from patients with no history of previous shoulder infection or surgery.

Methods Tendon, bursa, and bone specimens were collected during surgery, stored in sterile dry bottles, and sent to a hospital-associated laboratory for culture growth analysis in media for aerobic and anaerobic agents. Findings from 141 samples from 47 shoulders were analyzed.

Results The cultures were negative in 46 cases (97.8\%) and in 140 samples (99.2\%). The culture was positive in a single patient, with growth of Staphylococcus hominis from one of three specimens collected.

Conclusions The rates of bacterial growth were not consistent with the international literature, indicating the low effectiveness of laboratory methods used in Brazil.

Trabalho realizado no Hospital Alemão Oswaldo Cruz, São Paulo, SP, Brasil.

recebido

18 de Janeiro de 2021

aceito

12 de Abril de 2021

Publicado on-line

Outubro 25, 2021
DOI https://doi.org/

$10.1055 / \mathrm{s}-0041-1735170$ ISSN 0102-3616.
(C) 2021. Sociedade Brasileira de Ortopedia e Traumatologia. All rights reserved.

This is an open access article published by Thieme under the terms of the Creative Commons Attribution-NonDerivative-NonCommercial-License, permitting copying and reproduction so long as the original work is given appropriate credit. Contents may not be used for commercial purposes, or adapted, remixed, transformed or built upon. (https://creativecommons.org/ licenses/by-nc-nd/4.0/)

Thieme Revinter Publicações Ltda., Rua do Matoso 170, Rio de Janeiro, RJ, CEP 20270-135, Brazil 


\section{Introdução}

A infecção é uma das mais temidas complicações relacionadas às cirurgias ortopédicas, pois agrega grande morbidade e elevação dos custos do tratamento. ${ }^{1-5} \mathrm{Na}$ literatura nacional, a taxa de infecção associada a uma artroplastia do ombro é de até $9,5 \%,{ }^{6}$ e chega a até $15 \%$ na literatura internacional ${ }^{7}$; nas artroscopias, esta taxa pode chegar a 3,4\% e, em cirurgias abertas para reparo do manguito rotador ou osteossíntese, ela é de até 1,9\%. ${ }^{7}$ Alguns autores discutem o significado do crescimento bacteriano e seu real papel fisiopatológico na soltura de componentes protéticos, na rigidez articular, na pseudoartrose, na instabilidade e na dor residual dos ombros operados. ${ }^{8-10}$

o Cutibacterium acnes, germe bacteriano anaeróbio grampositivo, lipofílico, não esporulado e de crescimento lento, ${ }^{3,9,11}$ possui especial papel neste cenário. Ele tem sido isolado em até $41,8 \%$ das cirurgias primárias do ombro em pacientes sem clínica prévia de infecção. ${ }^{4,8,12-14}$

Embora esta bactéria seja componente da flora comensal da pele, onde coloniza os folículos pilosos e glândulas sebáceas, e tradicionalmente seja considerada não-patogênica, ${ }^{10}$ sua participação em uma série de infecções foi demonstrada, sobretudo relacionada a adesão bacteriana nos implantes ortopédicos e formação de biofilme. ${ }^{15}$ As cirurgias no ombro envolvem grande risco, devido à proximidade do sítio cirúrgico à axila, sede de numerosos folículos pilosos e glândulas sebáceas; ${ }^{7}$ por isso, existe maior colonização no ombro do que em outras articulações, como o joelho e o quadril. Pelo mesmo motivo, verifica-se maior incidência de infecções pelo $C$. acnes no sexo masculino. ${ }^{14}$

A contaminação mais comum do $C$. acnes é por meio da migração do germe que coloniza a pele adjacente ao sítio cirúrgico para os tecidos mais profundos após a incisão. Outras possíveis contaminações ocorrem pela manipulação do sítio cirúrgico e dos materiais cirúrgicos pela equipe hospitalar e pela disseminação hematogênica do microrganismo aderido aos implantes prévios. Dentre os métodos desenvolvidos para o diagnóstico bacteriológico, destaca-se a cultura de amostras profundas. ${ }^{15,16}$

O objetivo do presente estudo é tentar identificar o crescimento bacteriano em cirurgias abertas e por artroscopia em ombros que não foram previamente operados.

\section{Casuística e Métodos}

Trata-se de um estudo prospectivo, transversal, sequencial, observacional, com avaliação dos resultados de culturas obtidas nas cirurgias de ombro e levantamento de dados clínicos dos pacientes, com análise estatística.

Foram analisados os resultados das culturas de 64 ombros de 63 pacientes submetidos a cirurgia primária do ombro entre abril de 2019 e maio de 2020. A média de idade dos pacientes foi de 59 anos, variando de 18 a 85 anos. Destes pacientes, 33 $(52,4 \%)$ eram do sexo masculino e $30(47,6 \%)$ eram do feminino. Foi realizada artroscopia do ombro em 46 (71,9\%) pacientes. Dentre os submetidos a procedimento aberto, 6 $(9,4 \%)$ realizaram osteossíntese, $6(9,4 \%)$ realizaram cirurgia para instabilidade, $4(6,2 \%)$ realizaram artroplastia do ombro e $2(3,1 \%)$ realizaram reparo do manguito rotador (-Tabela $\mathbf{1}$ ).
Tabela 1 Indivíduos incluídos no estudo, segundo tempo de seguimento clínico, técnica cirúrgica, diagnóstico, gênero,

idade e crescimento bacteriano nas culturas

\begin{tabular}{|c|c|c|c|c|c|c|}
\hline$n^{\circ}$ & $\begin{array}{l}\text { Seguimento } \\
\text { (em meses) }\end{array}$ & Técnica & Diagnóstico & Gênero & idade & Culturas \\
\hline 1 & 19 & A & 3 & $\mathrm{~F}$ & 79 & $(-)$ \\
\hline 2 & 19 & A & 3 & $\mathrm{~F}$ & 67 & $(-)$ \\
\hline 3 & 18 & B & 1 & M & 54 & $(-)$ \\
\hline 4 & 18 & B & 1 & $\mathrm{~F}$ & 69 & $(-)$ \\
\hline 5 & 18 & B & 1 & M & 66 & $(-)$ \\
\hline 6 & 18 & A & 3 & M & 18 & $(+)$ \\
\hline 7 & 18 & B & 1 & $\mathrm{~F}$ & 68 & $(-)$ \\
\hline 8 & 18 & B & 1 & $\mathrm{~F}$ & 60 & $(-)$ \\
\hline 9 & 17 & B & 3 & $\mathrm{~F}$ & 43 & $(-)$ \\
\hline 10 & 17 & B & 1 & $\mathrm{M}$ & 36 & $(-)$ \\
\hline 11 & 17 & B & 3 & $M$ & 30 & $(-)$ \\
\hline 12 & 17 & A & 2 & $\mathrm{~F}$ & 85 & $(-)$ \\
\hline 13 & 17 & B & 1 & $\mathrm{~F}$ & 71 & $(-)$ \\
\hline 14 & 16 & A & 3 & M & 77 & $(-)$ \\
\hline 15 & 16 & B & 1 & M & 51 & $(-)$ \\
\hline 16 & 16 & B & 1 & M & 71 & $(-)$ \\
\hline 17 & 16 & B & 1 & $\mathrm{~F}$ & 41 & $(-)$ \\
\hline 18 & 16 & A & 3 & M & 37 & $(-)$ \\
\hline 19 & 16 & A & 1 & M & 53 & $(-)$ \\
\hline 20 & 15 & A & 1 & M & 54 & $(-)$ \\
\hline 21 & 15 & A & 1 & M & 72 & $(-)$ \\
\hline 22 & 15 & A & 1 & $\mathrm{~F}$ & 68 & $(-)$ \\
\hline 23 & 14 & A & 1 & M & 75 & $(-)$ \\
\hline 24 & 14 & B & 3 & $\mathrm{M}$ & 40 & $(-)$ \\
\hline 25 & 14 & A & 1 & $\mathrm{M}$ & 75 & $(-)$ \\
\hline 26 & 14 & A & 1 & $\mathrm{M}$ & 58 & $(-)$ \\
\hline 27 & 13 & $\mathrm{~A}$ & 1 & M & 68 & $(-)$ \\
\hline 28 & 13 & A & 1 & $M$ & 70 & $(-)$ \\
\hline 29 & 13 & A & 1 & $\mathrm{~F}$ & 65 & $(-)$ \\
\hline 30 & 13 & A & 1 & $\mathrm{~F}$ & 66 & $(-)$ \\
\hline 31 & 12 & A & 1 & $\mathrm{~F}$ & 75 & $(-)$ \\
\hline 32 & 12 & A & 1 & $\mathrm{~F}$ & 74 & $(-)$ \\
\hline 33 & 12 & A & 1 & $\mathrm{~F}$ & 77 & $(-)$ \\
\hline 34 & 11 & В & 3 & $\mathrm{M}$ & 28 & $(-)$ \\
\hline 35 & 11 & A & 1 & $\mathrm{M}$ & 55 & $(-)$ \\
\hline 36 & 11 & A & 1 & $\mathrm{M}$ & 56 & $(-)$ \\
\hline 37 & 11 & B & 3 & $\mathrm{M}$ & 63 & $(-)$ \\
\hline 38 & 10 & A & 1 & $\mathrm{~F}$ & 55 & $(-)$ \\
\hline 39 & 10 & A & 1 & $\mathrm{M}$ & 60 & $(-)$ \\
\hline 40 & 10 & A & 1 & $\mathrm{M}$ & 31 & $(-)$ \\
\hline 41 & 9 & A & 3 & $\mathrm{M}$ & 21 & $(-)$ \\
\hline 42 & 9 & B & 1 & $\mathrm{~F}$ & 80 & $(-)$ \\
\hline 43 & 9 & B & 2 & $\mathrm{~F}$ & 77 & $(-)$ \\
\hline 44 & 9 & A & 3 & M & 34 & $(-)$ \\
\hline
\end{tabular}


Tabela 1 (Continued)

\begin{tabular}{|l|l|l|l|l|l|l|}
\hline$n^{\circ}$ & $\begin{array}{l}\text { Seguimento } \\
\text { (em meses) }\end{array}$ & Técnica & Diagnóstico & Gênero & idade & Culturas \\
\hline 45 & 9 & A & 1 & F & 46 & $(-)$ \\
\hline 46 & 8 & A & 1 & F & 58 & $(-)$ \\
\hline 47 & 8 & A & 1 & F & 84 & $(-)$ \\
\hline
\end{tabular}

Abreviações: $A$, técnica artroscópica; $B$, técnica aberta; 1 ; lesão do manguito rotador; 2 , artrose; 3 , trauma; $(+)$, houve crescimento bacteriano nas culturas; (-), não houve crescimento bacteriano nas culturas; 0 , resultado das culturas indisponível.

Os critérios de inclusão foram: pacientes $>18$ anos, sem história prévia de infecção no ombro e submetidos a cirurgia primária nesta articulação. Foram excluídos os pacientes com história de cirurgia e/ou infecção prévias no ombro.

Nos procedimentos abertos, a preparação da pele seguiu o padrão utilizado para pacientes que são submetidos a osteossíntese ou artroplastia: degermação cuidadosa do ombro, braço, antebraço, mão e axila com solução iodopovidona (PVP-I) a 10\%, preparação do sítio cirúrgico com PVP-I a 10\% alcoólica em 2 camadas e envelopagem do sítio cirúrgico com campo incisional antimicrobiano de adesivo acrílico hipoalergênico impregnado de iodo (Ioban).

Nos pacientes submetidos a cirurgia artroscópica, a preparação seguiu outro protocolo, composto por degermação cuidadosa do ombro, braço, antebraço, mão e axila com solução de gluconato de clorexidina a $4 \%$ e preparação do sítio cirúrgico com clorexidina alcoólica a 2\% em 2 camadas, sem envelopagem.

Todos os pacientes receberam infusão de cefuroxima 1,5 g durante a indução anestésica e durante 24 horas após o procedimento.

As amostras intraoperatórias de $0,5 \mathrm{~cm}^{3}$ de osso (úmero, acrômio ou clavícula), tendão (tendão da cabeça longa do bíceps ou tendão conjunto) e bolsa subacromial foram utilizadas para análise laboratorial da proliferação de bactérias em meios de cultura. Estas amostras foram coletadas em frascos estéreis a seco, sem adicional de outro substrato, sem permitir contato com o campo cirúrgico, luvas, aventais ou qualquer outro equipamento. $\mathrm{Em}<1$ hora de intervalo, os frascos foram levados pela equipe de apoio hospitalar ao laboratório credenciado do hospital.

No laboratório, as amostras foram manipuladas em cabine de segurança microbiológica. Os fragmentos ósseos foram inoculados apenas em meio de tioglicolato (-Figura 1). $\mathrm{O}$ meio foi incubado por até 72 horas a $36^{\circ} \mathrm{C} \pm 1^{\circ} \mathrm{C}$. Em caso de turvação, o meio foi subcultivado em ágar sangue de carneiro a 5\% (- Figura 2) e incubado por até 72 horas em atmosfera de $5 \%$ de $\mathrm{CO}_{2}$ a $36^{\circ} \mathrm{C} \pm 1^{\circ} \mathrm{C}$. Os tecidos não ósseos foram homogeneizados assepticamente, utilizando-se bisturi descartável estéril e $\sim 0,5 \mathrm{ml}$ de solução salina fisiológica estéril. Para a cultura para aeróbios, alíquotas de $\sim 0,05 \mathrm{ml}$ do homogeneizado foram semeadas em meio de tioglicolato e ágar chocolate suplementado (-Figura 2). 0 meio de tioglicolato foi incubado por até 72 horas a $36^{\circ} \mathrm{C} \pm 1^{\circ} \mathrm{C}$. As placas foram incubadas por até 72 horas em atmosfera de $5 \%$ de $\mathrm{CO}_{2}$ a $36^{\circ}$

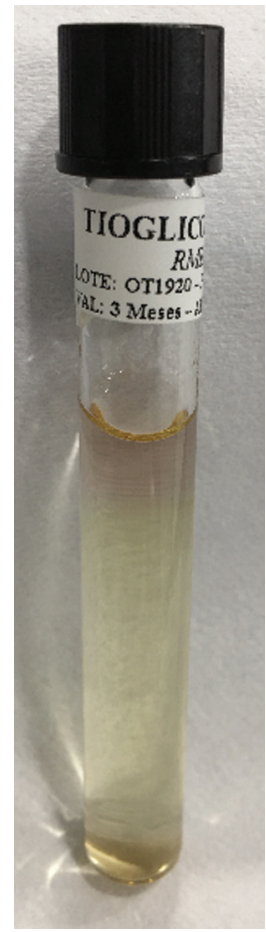

Fig. 1 Tubo com meio de tioglicolato utilizado na semeadura de amostras clínicas.

$\mathrm{C} \pm 1^{\circ} \mathrm{C}$, sendo inspecionadas diariamente quanto à presença de colônias. Para cultura para anaeróbios, o homogeneizado foi semeado em ágar Brucella com sangue de equino e suplementado com hemina e NAD, e foi também semeado em meio de tioglicolato. As placas e o tubo foram incubados por até 7 dias em anaerobiose.

Em caso de presença de colônias nos meios sólidos, estas foram identificadas por espectrometria de massas. Em casos de ausência de colônias nas placas e de turvação do meio de tioglicolato na cultura para aeróbios, este foi subcultivado em ágar sangue de carneiro e a placa foi incubada por até 72 horas em atmosfera de $5 \%$ de $\mathrm{CO}_{2}$ a $36^{\circ} \mathrm{C} \pm 1^{\circ} \mathrm{C}$, sendo inspecionadas diariamente quanto à presença de colônias. Na rotina de anaeróbios, em caso de ausência de colônias nas placas e de turvação do meio de tioglicolato, o caldo foi subcultivado em ágar sangue suplementado e incubado em anaerobiose por 72 horas. As colônias obtidas em meio sólido foram identificadas por espectrometria de massas.

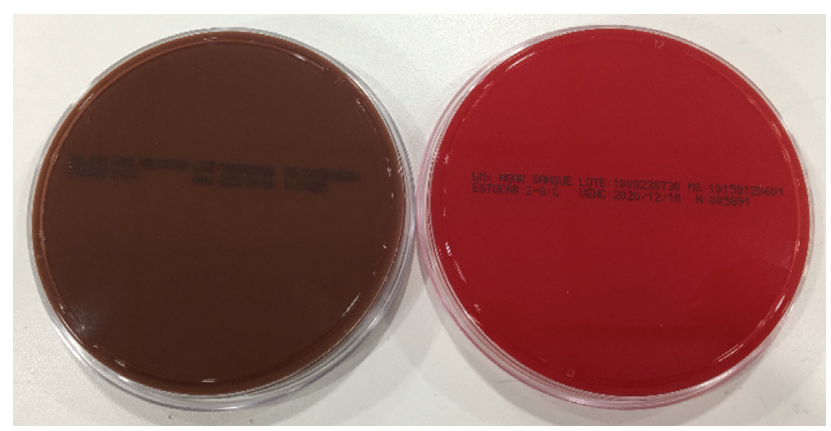

Fig. 2 Placas de ágar chocolate e ágar sangue utilizadas na semeadura de amostras clínicas. 
Tabela 2 Resultados de culturas de amostras intraoperatórias. As linhas indicam os resultados das amostras coletadas por paciente (positivo ou negativo); as colunas indicam as cirurgias realizadas (abertas ou fechadas)

\begin{tabular}{|l|l|l|l|}
\hline & Abertas & Fechadas & Todas \\
\hline Culturas positivas & 1 & 0 & 1 \\
\hline Culturas negativas & 9 & 37 & 46 \\
\hline Todas & 10 & 37 & 47 \\
\hline
\end{tabular}

Foram coletados e enviados para cultura 189 fragmentos de tecido dos 63 ombros operados. Dezesseis indivíduos foram excluídos: 15 não apresentavam resultados de culturas, pois houve extravio das amostras, e 1 paciente foi excluído por não se enquadrar nos critérios de inclusão (realizou artroplastia do ombro previamente). Restaram 47 ombros (141 amostras), os quais constituíram nossa casuística final.

O presente trabalho foi aprovado pelo Comitê de Ética em Pesquisa (CAAE: 34265620.5.0000.0070). Todos os pacientes do presente estudo assinaram o termo de consentimento livre e esclarecido para participar do estudo. 0 presente estudo não apresenta conflito de interesses.

\section{Resultados}

Dos 47 ombros incluídos no estudo, totalizando a coleta e a análise de 141 fragmentos de tecidos, obtivemos resultados de culturas negativas em 46 casos $(97,8 \%)$ e em 140 amostras (99,2\%).

Apenas um paciente apresentou resultado positivo, com crescimento bacteriano do Staphylococcus hominis em uma das três amostras coletadas. Este paciente é do sexo masculino e foi submetido a cirurgia aberta para instabilidade anterior do ombro. Ele foi avaliado de acordo com dados clínicos e exames complementares (radiografias seriadas, hemograma, proteína $C$ reativa e velocidade de hemossedimentação) para o diagnóstico de eventual quadro clínico infeccioso do ombro. Na finalização do presente estudo, o paciente apresenta-se com 12 meses de seguimento pósoperatório e não apresentou soltura do material de síntese (parafusos canulados com arruelas), nem aumento das provas inflamatórias, queixas de dor residual, limitação funcional ou recidiva da instabilidade.

Em relação ao seguimento dos demais pacientes, nenhum apresentou qualquer queixa clínica sugestiva de infecção (dor, hiperemia, edema, calor ou drenagem de secreção).

A população total do estudo encontra-se disposta na -Tabela 1. A disposição dos resultados encontra-se na - Tabela 2.

\section{Discussão}

Salientamos a importância do nosso estudo em iniciar na literatura nacional a abordagem científica do C. acnes, agente bacteriano atribuído a grande incidência de infecção pós- cirúrgicas do ombro. As amostras foram enviadas da cirurgia para o laboratório especializado e credenciado do hospital, que utiliza protocolo para pesquisa de bactérias aeróbicas e anaeróbicas, sendo considerado um dos maiores e mais importantes e conceituados centros laboratoriais do nosso país.

Hudek et al. ${ }^{12}$ demonstraram uma incidência de 36,4\% de amostras intraoperatórias positivas para $C$. acnes em pacientes sem história prévia de infecção submetidos a cirurgias primárias abertas para reparo do manguito rotador, descompressão subacromial, artroplastia e correção de instabilidade anterior do ombro. Para artroplastias primárias do ombro, Levy et al. ${ }^{14}$ evidenciaram uma taxa ainda maior: $41,8 \%$. No nosso estudo, não observamos a replicação de tais valores. A análise das metodologias desses estudos nos mostra que a seleção dos pacientes seguiu critérios semelhantes. As medidas de antissepsia e assepsia desses estudos foram semelhantes às nossas, com o diferencial do uso da solução iodada na degermação em vez de clorexidina no nosso estudo. Quanto à escolha de amostras, ${ }^{12}$ Hudek et al. ampliaram a base do estudo, realizando coleta de sítios superficiais, enquanto Levy et al. ${ }^{14}$ selecionaram amostras apenas de tecidos profundos. Outro diferencial entre esses estudos foi a utilização por Hudek et al. ${ }^{12}$ de frascos contendo solução de tioglicolato (meio próprio para o cultivo de agentes anaeróbios) para armazenamento imediato das amostras, enquanto Levy et al. ${ }^{14}$ realizaram armazenamento imediato a seco das amostras. Tanto o armazenamento quanto a metodologia de coleta de materiais do nosso estudo seguiram o modelo de Levy et al. ${ }^{14}$

Um fator importante a se considerar para a pesquisa de $C$. acnes é o tempo de incubação das culturas. A literatura evidencia uma média de 6 dias para o seu crescimento, variando entre 2 e 15 dias. ${ }^{16}$ A pesquisa para agentes anaeróbios realizada pelo laboratório utilizado no nosso estudo possui como padrão um tempo de cultura de até 5 dias. Este intervalo, inferior ao necessário para o crescimento do $C$. acnes, ${ }^{1,17}$ permite apenas o crescimento de uma menor série de agentes. $\mathrm{O}$ achado único do $\mathrm{S}$. hominis demonstra a ineficiência da incubação em 7 dias para uma pesquisa ampla e sugere o subdiagnóstico de contaminação de tecidos profundos pelo $C$. acnes, uma vez que os estafilococos coagulasenegativos são os agentes mais associados ao mesmo. ${ }^{16}$ Consideramos que o protocolo de pesquisa se mostra ineficiente para a análise correta de agentes bacterianos, principalmente do $C$. acnes.

O meio de armazenamento das amostras imediatamente após a coleta até o processamento laboratorial também merece atenção, principalmente na pesquisa de agentes anaeróbios. A inoculação em meio nutritivo imediato e a prevenção do contato com o ar ambiente, vedando-se os frascos, podem preservar a sobrevivência e favorecer o crescimento bacteriano anaeróbio.

A literatura evidencia taxas menores de infecção no ombro após artroscopias em relação aos procedimentos abertos, $^{7}$ já que as artroscopias possuem incisões mais limitadas, menor manipulação de tecidos, e as feridas são submetidas a um intenso processo de lavagem com soro 
fisiológico durante praticamente todo o ato operatório. No nosso estudo, a maioria dos procedimentos cirúrgicos foi artroscópica $(71,9 \%)$. Isoladamente, isso não justifica o fato de não termos obtido nenhum caso de crescimento bacteriano nas artroscopias. Nas cirurgias abertas, a via cirúrgica mais utilizada no nosso estudo foi a deltopeitoral. Tal via implica uma taxa duas vezes menor de crescimento do $C$. acnes do que nas vias anterolaterais do ombro, uma vez que se supõe haver maior colonização ao redor do acrômio. ${ }^{12}$ Ressaltamos que, apesar destas considerações serem importantes para a análise da menor incidência de $C$. acnes em relação à literatura, não houve significância estatística entre a relação da cirurgia aberta ou fechada para a positividade da cultura $(p=0,213)$.

O típico quadro clínico insidioso e frustro das infecções pelo $C$. acnes não nos guia quanto à possibilidade de estarmos diante de uma possível complicação pós-operatória ao longo prazo, embora saibamos que sua significativa habitação adjacente ao sítio cirúrgico seja um risco aumentado nas cirurgias do ombro. ${ }^{16}$ Em revisão de 75 pacientes submetidos a revisão artroplástica do ombro por falha do material, Topolski et al. ${ }^{18}$ evidenciaram $60 \%$ de crescimento de $C$. acnes. Desse modo, observamos a importância da identificação e do estudo deste agente para a adaptação de melhores medidas antissépticas e assépticas para o sucesso terapêutico da cirurgia do ombro.

Com relação ao único caso em que ocorreu crescimento bacteriano, salientamos que ele não apresentou quadro compatível com infecção no ombro, uma vez que não preencheu nenhum critério clínico, laboratorial ou radiográfico, ficando evidente o diagnóstico de contaminação da amostra. ${ }^{19}$

Consideramos que a grande importância do presente estudo é a de alertar a baixa eficácia dos métodos atualmente utilizados no Brasil para identificação bacteriana, mesmo nos maiores laboratórios.

Estudos adicionais, seguindo padrões de antissepsia e assepsia bem definidos como no nosso estudo, mas alterando a metodologia laboratorial, com padronização da seleção de meio de armazenamento e cultivo próprio para anaeróbios, maior tempo de incubação de culturas do que o empregado convencionalmente pelos laboratórios para pesquisa de agentes anaeróbios, e que proporcionem avaliação e comparação das metodologias de pesquisa microbiológica mais recentes (espectrometria de massa e sequenciamento genético) são essenciais para uma análise mais fidedigna da real atividade e importância do $C$. acnes em nosso meio. Visando contemplar todos esses fatores, nosso grupo possui um novo estudo em andamento, utilizando tubos com caldo de tioglicolato para o armazenamento imediato de amostras após a coleta cirúrgica, tempo de incubação de amostras mínimo de 14 dias e espectrometria de massa de rotina para as culturas positivas.

\section{Conclusão}

Não evidenciamos taxas de crescimento bacteriano condizentes com a literatura internacional nas amostras de tecidos de ombros submetidos a cirurgias primárias que foram coletadas e cultivadas em um laboratório considerado referência no meio, seguindo os métodos habituais.

\section{Suporte Financeiro}

Não houve suporte financeiro de fontes públicas, comerciais, ou sem fins lucrativos.

\section{Conflito de Interesses}

Os autores declaram não haver conflito de interesses.

\section{Referências}

1 Gomes LSM. Early Diagnosis of Periprosthetic Joint Infection of the Hip-Current Status, Advances, and Perspectives. Rev Bras Ortop (Sao Paulo) 2019;54(04):368-376

2 Ahsan ZS, Somerson JS, Matsen FA 3rd. Characterizing the Propionibacterium Load in Revision Shoulder Arthroplasty: A Study of 137 Culture-Positive Cases. J Bone Joint Surg Am 2017;99(02): 150-154

3 Qiu B, Al K, Pena-Diaz AM, et al. Cutibacterium acnes and the shoulder microbiome. J Shoulder Elbow Surg 2018;27(10): 1734-1739

4 Torrens C, Marí R, Alier A, Puig L, Santana F, Corvec S. Cutibacterium acnes in primary reverse shoulder arthroplasty: from skin to deep layers. J Shoulder Elbow Surg 2019;28(05):839-846

5 Bonnevialle $\mathrm{N}$, Dauzères F, Toulemonde J, Elia F, Laffosse JM, Mansat P. Periprosthetic shoulder infection: an overview. EFORT Open Rev 2017;2(04):104-109

6 Nagaya LH, Salles MJC, Takikawa LSC, et al. Infections after shoulder arthroplasty are correlated with higher anesthetic risk score: a case-control study in Brazil. Braz J Infect Dis 2017;21(06): 613-619

7 Shi LL, Von Kuedell AG, Higgins Dl. Treatment of shoulder infections after arthroscopy, open surgery, or arthroplasty. Curr Orthop Pract 2012;23(01):23-28

8 Padegimas EM, Lawrence C, Narzikul AC, et al. Future surgery after revision shoulder arthroplasty: the impact of unexpected positive cultures. J Shoulder Elbow Surg 2017;26(06):975-981

9 Howlin RP, Winnard C, Angus EM, et al. Prevention of Propionibacterium acnes biofilm formation in prosthetic infections in vitro. J Shoulder Elbow Surg 2017;26(04):553-563

10 Lutz MF, Berthelot P, Fresard A, et al. Arthroplastic and osteosynthetic infections due to Propionibacterium acnes: a retrospective study of 52 cases, 1995-2002. Eur J Clin Microbiol Infect Dis 2005;24(11):739-744

11 Koh CK, Marsh JP, Drinković D, Walker CG, Poon PC. Propionibacterium acnes in primary shoulder arthroplasty: rates of colonization, patient risk factors, and efficacy of perioperative prophylaxis. J Shoulder Elbow Surg 2016;25(05):846-852

12 Hudek R, Sommer F, Kerwat M, Abdelkawi AF, Loos F, Gohlke F. Propionibacterium acnes in shoulder surgery: true infection, contamination, or commensal of the deep tissue? J Shoulder Elbow Surg 2014;23(12):1763-1771

13 Clark JJC, Abildgaard JT, Backes J, Hawkins RJ. Preventing infection in shoulder surgery. J Shoulder Elbow Surg 2018;27(07):1333-1341

14 Levy O, Iyer S, Atoun E, et al. Propionibacterium acnes: an underestimated etiology in the pathogenesis of osteoarthritis? J Shoulder Elbow Surg 2013;22(04):505-511

15 Achermann Y, Goldstein EJ, Coenye T, Shirtliff ME. Propionibacterium acnes: from commensal to opportunistic biofilm-associated implant pathogen. Clin Microbiol Rev 2014;27(03):419-440

16 Boisrenoult P. Cutibacterium acnes prosthetic joint infection: Diagnosis and treatment. Orthop Traumatol Surg Res 2018;104 (1S):S19-S24 
17 Elston MJ, Dupaix JP, Opanova MI, Atkinson RE. Cutibacterium acnes (formerly Proprionibacterium acnes) and Shoulder Surgery. Hawaii J Health Soc Welf 2019;78(11, Suppl 2) 3-5

18 Topolski MS, Chin PY, Sperling JW, Cofield RH. Revision shoulder arthroplasty with positive intraoperative cultures: the value of preoperative studies and intraoperative histology. J Shoulder Elbow Surg 2006;15(04):402-406

19 Assunção JH, Noffs GG, Malavolta EA, Gracitelli MEC, Lima ALM, Ferreira Neto AA. Septic arthritis of the shoulder and elbow: one decade of epidemiological analysis at a tertiary referral hospital. Rev Bras Ortop 2018;53(06):707-713 